\title{
The Use of Low Molecular Weight Heparin for Venous Thromboembolism Prophylaxis in Medical Patients: How Much Are We Adherent to the Guidelines?
}

\author{
Lamia AlHajri' ${ }^{1}$, Nicole Gebran ${ }^{2}$ \\ ${ }^{1}$ Higher Colleges of Technology, Health Sciences Division, Dubai, United Arab Emirates \\ ${ }^{2}$ Tawam Hospital in Affiliation with John Hopkins, AlAin, United Arab Emirates \\ Email: Lamia-alhajri@live.com
}

Received 13 October 2015; accepted 29 November 2015; published 2 December 2015

Copyright (C) 2015 by authors and Scientific Research Publishing Inc.

This work is licensed under the Creative Commons Attribution International License (CC BY). http://creativecommons.org/licenses/by/4.0/

(c) (i) Open Access

\section{Abstract}

Background: Venous thromboembolism (VTE) is a common complication seen during or after hospitalization that manifests as deep venous thrombosis (DVT) and/or pulmonary embolism (PE). $\mathrm{PE}$ is considered the commonest preventable cause of death during and/or after hospitalization. Thus, pharmacological and mechanical methods are used to prevent VTE in hospitalized patients. Despite the availability of guidelines for VTE prophylaxis, it is crucial to assess the adherence and adaptation of the institution to these guidelines. Purpose: This study aimed to investigate adherence to the American College of Chest Physicians (ACCP) 2012 VTE prophylaxis guidelines in hospitalized medical patients in a tertiary care hospital in the United Arab Emirates. Methods: An observational prospective design was utilized in this study. To achieve the purpose, primary and secondary end points were identified to be the core of the investigation. The primary end points were: the incidence of bleeding, VTE, and cardiovascular events. While the secondary end points were: dose and indication validity for prophylaxis, VTE and bleeding risk assessments, adverse drug events (ADE) other than bleeding, appropriate monitoring when on low molecular weight heparin (LMWH) and the presence of contraindication at the time of prescribing LMWH. Results: 16 patients $(20 \%)$ out of the total 80 met one or more of the primary end points. The vast majority of patients $(81.25 \%)$ developed bleeding, while VTE was seen in one case only during hospitalization. 11 patients $(13.75 \%)$ received LMWH while a contraindication was present. 15 patients (18.75\%) who were prescribed LMWH had an International Medical Prevention Registry on Venous Thromboembolism (IMPROVE) bleeding risk score of $\geq 7$. However, 5 out of 13 patients (38.46\%) who developed bleeding had a bleeding score of $\geq 7$, and the relationship between bleeding score of $\geq 7$ and the development of bleeding was statistically significant $(p=0.047)$. When investigating the doses that were utilized, $40 \%$ were prescribed an inappropriate dose. 
Conclusion: Various factors played a role in the inappropriateness of VTE prophylaxis such as; poor adherence to VTE guidelines, inappropriate dosing and monitoring, and not evaluating the bleeding risk. Hence, to be able to achieve effective VTE prophylaxis, these factors need to be addressed through adherence to and adaptation of the ACCP 2012 VTE prophylaxis guidelines.

\title{
Keywords
}

\author{
Venous Thromboembolism (VTE), Deep Venous Thrombosis (DVT), Pulmonary Embolism (PE), \\ VTE Prophylaxis Guidelines, International Medical Prevention Registry on Venous \\ Thromboembolism (IMPROVE), Padua Risk Assessment Score
}

\section{Introduction}

VTE is a disease that might manifest as DVT and/or PE. DVT occurs by the formation of a blood clot (fibrin) in the veins of the lower extremities, often provoked by prolonged immobility and/or vascular injury. VTE can also occur with little or no provocation in patients who have an underlying hypercoagulable condition. DVT is further subdivided based on the involved vein into distal (calf) vein thrombosis and proximal vein thrombosis. The proximal vein thrombosis clinically is considered to be more important because of its close association with PE as per Thompson and Manninom (2003) [1]. Pulmonary embolism occurs when there is a block in the lung artery or any of its branches by emboli that mostly travels from the veins in the lower extremities.

Because VTE is one of the common complications seen during or after hospitalization, the importance of preventing such a complication was illustrated by several studies. Anderson et al. (2007) pointed out that $51 \%$ of total discharges in the United States (US) in 2003 were estimated as to be at risk of developing VTE [2]. Moreover, Anderson et al. (2007) mentioned that PE is considered the commonest preventable cause of death in hospitalized and post hospitalized patients [2]. In addition, Anderson et al. (2007), Dismuke and Wanger (1986) and Horlander et al. (2003) pointed out that the annual number of deaths in the US as a result of PE is estimated to be as high as 300,000 [2]-[4].

Pharmacological and mechanical methods have been implemented to overcome this problem. However, in this research the focus will be on the pharmacological methods; specifically the use of LMWH for VTE prophylaxis. Enoxaparin, tinzaparin and dalteparin are the 3 most commonly used LMWH in clinical settings. LMWH are small heparin fragments obtained by chemical or enzymatic depolymerization of unfractionated heparin (UFH). These agents produce their anticoagulation effects by the binding of specific pentasaccharide sequence to antithrombin (AT), resulting in inhibition of factor xa and to a less extent factor IIa (thrombin). LMWHs have an improved pharmacokinetics and pharmacodynamics properties compared to unfractionated heparin (UFH). LMWH offers a longer half-life that enables once or twice daily administration and a subcutaneous administration providing more practicality, convenience and compliance to patients. Routine monitoring and frequent dose adjustments are other advantages that are not required for the majority of cases compared to UFH. If monitoring of anticoagulation is required while on LMWH for various reasons like pregnancy or renal disease, anti-xa activity laboratory test is utilized [5].

Despite the fact that guidelines to prevent VTE in hospitalized medical patients are readily available, a critical question remains, how much are we adherent to these guidelines?

Tapson et al. (2007) mentioned that 6 of every 10 acutely ill patients who fulfill the criteria of the CHEST 2012 guidelines to receive VTE prophylaxis actually received it as referred in Table 1 [5] [6]. Moreover, the benefit of adherence to VTE prophylaxis guidelines was addressed in a number of studies. A before-after controlled study was done by Scaglione et al. (2005) to assess the influences of adherence to guidelines on achieving an effective VTE prophylaxis [7]. The study showed that among patients with high risk to develop VTE, adherence to guidelines improved VTE prophylaxis in medical patients were the percentages escalated from 25\% to $41.7 \%$ ( $p=0.0075)$ and in surgical patients from $63.7 \%$ to $97.1 \%(p=0.0004)$ [7]. On the other hand, Bateman et al. (2013) carried out a before-after observational study aiming to examine the differences arising on VTE risk assessment documentation and inappropriate prescribing of prophylaxis treatment plan after adopting the NICE guidelines for VTE prophylaxis [8]. The study showed that adherence to the guidelines resulted in a better documentation of the VTE risk assessment, as the percentages rose from 51.5\% in 2009 to $79.2 \%$ in 2010 
Table 1. Prevention of VTE in medical patients—Summary of CHEST 2012 guidelines for VTE prophylaxis [6].

\begin{tabular}{|c|c|}
\hline Risk group & Recommended prophylaxis \\
\hline Low VTE risk (Padua < 4) & Recommend against the use of pharmacologic or mechanical prophylaxis (Grade 1B) \\
\hline Low VTE risk (Paudua < 4) with high bleed risk & Recommend against anticoagulant thromboprophylaxis (Grade 1B) \\
\hline High VTE risk (Padua $\geq 4)$ & $\begin{array}{l}\text { Thromboprophylaxis with LMWH (Grade 1B), LDUH BID or TID (Grade 1B), or } \\
\text { fondaparinux (Grade 1B). }\end{array}$ \\
\hline High VTE risk (Padua $\geq 4$ ) with high bleed risk & $\begin{array}{l}\text { Mechanical thromboprophylaxis with graduated compression stockings (GCS) } \\
\text { (Grade 2C) or intermittent pneumatic compression (IPC) (Grade 2C). } \\
\text { When bleeding risk decreases suggest pharmacologic thromboprophylaxis is } \\
\text { substituted for mechanical thromboprophylaxis (Grade 2B). }\end{array}$ \\
\hline Extended duration of thromboprophylaxis & $\begin{array}{l}\text { Recommend against extending the duration of thromboprophylaxis beyond the } \\
\text { period of patient immobilization or acute hospital stay. }\end{array}$ \\
\hline
\end{tabular}

$(p<0.001)[8]$.

The aim of this study was to conduct a medication use evaluation (MUE) by assessing the adherence of VTE prophylaxis management in adult medical patients to the American College of CHEST Physicians (ACCP) 2012 guideline for VTE prophylaxis in medical patients [6]. To achieve this objective, the following end points were the core of the investigation:

1) Primary end points; incidence of bleeding, VTE, and cardiovascular events.

2) Secondary end points; dose validity, indication validity for VTE prophylaxis, bleeding risk assessment, adverse drug events (ADE) other than bleeding, appropriate monitoring when on LMWH and presence of contraindication $(\mathrm{C} / \mathrm{I})$ at the time of prescribing LMWH.

\section{Methodology}

\subsection{Study Design \& Location}

An observational prospective study design was utilized to investigate the primary and secondary end points. The study was conducted at Tawam Hospital in Affiliation with John Hopkins; a 468-bed tertiary care facility located in Al Ain district, Abu Dhabi city, United Arab Emirates.

\subsection{Data Collection $\&$ Sample Selection}

Data collection period started from January 1, 2014 until May 23, 2014. During this period the lists of patients hospitalized in the adult medical wards were accessed 3 days per week via the Cerner Millennium ${ }^{\circledR}$ Computerized Provider Order Entry (CPOE) to filter the patients that were prescribed LMWH for VTE prophylaxis purposes [9]. Then, the patients were followed until discharge and all events occurred during hospitalization were documented accordingly. However, if the patient was not discharged during the period of data collection, the last day of data collection was considered the discharge date.

Inclusion criteria: patients $\geq 18$ of any gender and ethnic group who were hospitalized in one of the adult medical wards for a reason other than surgery, and were given LMWH for VTE prophylaxis during the period of hospitalization. Oncology patients and pregnant females were included as well. All patients included in this study were on enoxaparin which was not intentional, but because enoxaparin is the most commonly used LMWH in Tawam hospital.

Exclusion criteria: surgical patients, patients given LMWH for VTE treatment and patients who have been hospitalized more than once during the period of data collection.

\subsection{Data Collection Methods}

The instrument that was used to gather all the information was Excel spread sheet (Microsoft office 2013). The sheet included as well the Padua and the IMPROVE scoring systems.

\subsection{Guidelines \& Scoring Systems}

The guideline used in this study to evaluate the adherence of the medical units to for VTE prophylaxis was the 
ACCP CHEST 2012 VTE prophylaxis guideline for medical patients [6]. As per the CHEST 2012 guidelines, to be able to achieve appropriate VTE prophylaxis 2 parameters has to be evaluated; the VTE risk and the bleeding risk [6]. Thus, to assess these parameters two scoring systems were utilized as seen in Table 2 and Table 3 . The Padua risk assessment score examines the risk of developing a VTE during hospitalization, and to determine whether or not VTE prophylaxis is needed [6]. As per the CHEST 2012 guidelines, VTE prophylaxis is required when the cumulative Padua score $\geq 4$, which reflects a high risk of developing VTE [6]. There are two methods for VTE prophylaxis, pharmacological and mechanical. To determine which option to choose for VTE prophylaxis the bleeding risk need to be investigated as well. The IMPROVE bleeding risk assessment score was used to evaluate the risk of bleeding and provide directions on whether to choose mechanical or pharmacological prophylactic measure [10]. A bleeding score of $\geq 7$ indicates a high risk of bleeding and in this case VTE prophylaxis is preferred to be mechanical [6].

\subsection{Analysis}

Continuous variables were presented by actual numbers $(\mathrm{N})$ and/or means $\pm \mathrm{SD}$, while the discrete variables were presented as percentages. In addition, the Chi-square test was used to establish the relationship between a

Table 2. Padua risk assessment tool [1] [6] [19]-[23].

\begin{tabular}{lc}
\hline \multicolumn{1}{c}{$\quad$ Padua risk assessment model } & Point \\
\hline Risk factor $^{*}$ Active Cancer $^{*}$ & 3 \\
Previous VTE & 3 \\
Reduced mobility $^{\circ}$ & 3 \\
Thrombophilic condition & 3 \\
Recent (<1 month) trauma/surgery & 2 \\
Age $\geq 70$ years & 1 \\
Heart or Respiratory Failure & 1 \\
Acute Myocardial Infarction or Ischemic Stroke & 1 \\
BMI $\geq 30$ & 1 \\
Ongoing Hormonal Treatment & 1 \\
Scores interpretation: Score $<4$ : Low VTE risk; Score $\geq 4$ : High VTE risk & 3 \\
\hline
\end{tabular}

*Active cancer is defined as local or distant metastases and with chemotherapy or radiation in the previous 6 months.

${ }^{\circ}$ Reduced mobility is defined as anticipated bed rest with bathroom privileges for at least 3 days.

Table 3. The IMPROVE bleeding risk assessment tool [10].

\begin{tabular}{lc}
\hline \multicolumn{1}{c}{ Risk factors } & Point \\
\hline Moderate renal failure (CrCl $30-50 \mathrm{ml} / \mathrm{min}$.) & 1 \\
Male Sex & 1 \\
Age 40 - 84 years & 1.5 \\
Active Cancer & 2 \\
Rheumatic disease & 2 \\
Central venous catheters & 2 \\
Admissions in Intensive Care & 2.5 \\
Severe Renal Failure (CrCl $<30 \mathrm{ml} / \mathrm{min}$.) & 2.5 \\
Liver insufficiency (INR $>1.5)$ & 2.5 \\
Age $\geq 85$ & 3.5 \\
Thrombocytopenia (<50 $\times 10^{9}$ cell/L) & 4 \\
Recent (3 months) bleeding & 4 \\
Active gastro-intestinal ulcer & 4 \\
High bleeding risk when total score $\geq 7$ & \\
\hline
\end{tabular}

If the score $\geq 7$, the overall rate of major bleedings is $7.9 \%$ and clinically relevant non-major bleedings is $4.1 \%$; If the score $<7$, the overall rate of major bleedings is $1.5 \%$ and clinically relevant non-major bleedings is $0.4 \%$. 
score of $\geq 7$ in the IMPROVE bleeding risk assessment score and the actual development of a bleeding incidence. Also, the Chi- square test was utilized to test the existence of a relationship between increased age and sensitivity to develop bleeding. Furthermore, the statistical analysis was carried out using Microsoft office excel 2013 and IBM SPSS Statistics V.21.

\subsection{Ethical Consideration}

This study was approved by Al Ain District Research Ethics Committee.

\section{Results}

\subsection{Patients' Characteristics}

A total number of 80 patients were eligible to be included in this study, and the baseline characteristics are presented in Table 4 . Forty of the study population $(50 \%)$ were $\geq 70$ years old. Forty-two females $(52.5 \%)$ were

Table 4. Baseline characteristics $(\mathrm{N}=80)$.

\begin{tabular}{|c|c|c|c|}
\hline Characteristics & Sub-Characteristic & Number of Patients/values & Percentage \\
\hline \multirow{4}{*}{ Age } & $<40$ years old & 70 & $8.75 \%$ \\
\hline & $40-59$ & 15 & $18.75 \%$ \\
\hline & $60-69$ & 18 & $22.5 \%$ \\
\hline & $\geq 70$ & 40 & $50 \%$ \\
\hline \multirow{2}{*}{ Gender } & Male & 38 & $47.5 \%$ \\
\hline & Female & 42 & $52.5 \%$ \\
\hline \multirow{2}{*}{ Height } & Mean of height $( \pm S D)$ & $155.4 \mathrm{~cm}( \pm 18.94)$ & - \\
\hline & Height was not documented & 6 & $7.5 \%$ \\
\hline \multirow{2}{*}{ Weight } & Mean of weight $( \pm S D)$ & $71.4 \mathrm{~kg}( \pm 25.42)$ & - \\
\hline & Weight was not documented & 3 & $3.75 \%$ \\
\hline \multirow{6}{*}{$\mathrm{BMI}^{\mathrm{a}}$} & $\mathrm{BMI} \leq 18$ & 10 & $12.5 \%$ \\
\hline & BMI 18.5 - 25 & 22 & $27.5 \%$ \\
\hline & BMI 26 - 29 & 16 & $20 \%$ \\
\hline & $\mathrm{BMI} \geq 30$ & 19 & $23.75 \%$ \\
\hline & $\mathrm{BMI}>40$ & 8 & $10 \%$ \\
\hline & BMI not documented & 5 & $6.25 \%$ \\
\hline \multirow{4}{*}{$\begin{array}{c}\text { Renal function } \\
\text { Creatinine clearance }(\mathrm{CrCl})\end{array}$} & $\mathrm{CrCl}>30 \mathrm{ml} /$ minute & 67 & $83.75 \%$ \\
\hline & $\mathrm{CrCl}<30 \mathrm{ml} /$ minutes & 7 & $8.75 \%$ \\
\hline & Dialysis & 4 & $5 \%$ \\
\hline & $\mathrm{CrCl}$ was not possible to calculate & 2 & $2.5 \%$ \\
\hline \multirow{2}{*}{ Hepatic function (acute/ chronic) } & Presence of hepatic dysfunction & 3 & $3.75 \%$ \\
\hline & Absence of hepatic dysfunction & 77 & $96.25 \%$ \\
\hline \multirow{6}{*}{ Thrombophilic condition } & Cancer & 8 & $10 \%$ \\
\hline & Hormonal Therapy & 1 & $1.25 \%$ \\
\hline & Obesity & 16 & $20 \%$ \\
\hline & Ulcerative colitis & 1 & $1.25 \%$ \\
\hline & Inflammatory bowel disease & 1 & $1.25 \%$ \\
\hline & Pregnancy & 1 & $1.25 \%$ \\
\hline \multirow{4}{*}{ Medications that increase bleeding risk } & Aspirin only & 27 & $33.75 \%$ \\
\hline & Clopidogrel only & 6 & $7.5 \%$ \\
\hline & Aspirin and clopidogrel & 10 & $12.5 \%$ \\
\hline & None & 37 & $46.25 \%$ \\
\hline
\end{tabular}

BMI $\left(\mathrm{kg} / \mathrm{m}^{2}\right)$ interpretations: 18.5—underweight; 18.5 to 24.9 - Normal range; 25.0 - 30.0—Obese; >30—Morbidly obese. 
included in the study, with 1 pregnant female among them. With regards to the body mass index (BMI), 27 patients (33.75\%) were morbidly obese, while 5 (6.25\%) did not have a documented BMI, and manual calculation of BMI was not possible because height and/or weight were not documented as well. While assessing the renal function of the study population using Cockroft-Gault equation, data illustrated that 67 of the study population $(83.75 \%)$ had a creatinine clearance $(\mathrm{CrCl})>30 \mathrm{ml} / \mathrm{min}$ at the time of prescribing the medication. However, calculating $\mathrm{CrCl}$ was not possible in 2 patients due to the missing data on weight. Moreover, when investigating the hepatic function of the study population the results showed that the majority (77 out of 80) of the population had no existing hepatic dysfunctional condition (acute or chronic). Furthermore, the patients were evaluated for the presence of thrombophilic conditions which are summarized in Table 5. The reason behind the need to investigate thrombophilic conditions is that thrombophilic conditions increase the risk of developing VTE and because it is needed to calculate the Padua score. The data revealed that 28 patients had pre-existing thrombophilic conditions, and of these obesity made up the majority (57.14\%). In addition, 43 patients (53.75\%) were on medications that can increase the risk of bleeding, and aspirin (ASA) was the most commonly used one.

\subsection{Primary and Secondary Endpoints}

Table 6 and Table 7 display the results of the primary and secondary end points. Two patients (2.5\%) died during the period of hospitalization, and the death was not related to the use of LMWH. A total number of 16 patients (20\%) met one or more of the primary end points. Yet, the vast majority (81.25\%) of these patients developed bleeding as a primary end point whether it was confirmed or possibly due to LMWH. The percentage of patients who received LMWH while a C/I was present at the time of prescribing was found to be 11 patients (13.75\%). On the other hand, due to an inappropriate initial investigation and documentation, the presence of C/I was not possible to be ruled out in 2 patients. Uncontrolled hypertension (HTN) was the major C/I (90.9\%) seen among patients, while only one patient had major bleeding at the time of prescribing.

As mentioned previously, to prevent VTE effectively and appropriately the Padua and IMPROVE scores need to be utilized. After calculating the Padua and IMPROVE scores for each patient, the results indicated that 15 patients (18.75\%) who were prescribed LMWH had a bleeding risk score of $\geq 7$. Five (38.46\%) of who developed bleeding during hospitalization had a bleeding risk score of $\geq 7$. Another major issue is dose appropriateness that requires the availability of 3 important parameters; $\mathrm{CrCl}$, BMI and weight in Kilogram (kg). Forty-five patients (56.25\%) were given a correct VTE prophylaxis dose, while 32 (40\%) were given an inappropriate dose, which is defined as under dose or over dose. Additionally, only 2 patients were suspected to have developed heparin induced thrombocytopenia (HIT).

Table 5. Thrombophilic conditions [10].

\begin{tabular}{|c|c|}
\hline Congenital & Acquired \\
\hline $\begin{array}{l}\text { Type II: } \\
\text { - Factor V Leiden (a mutation in the F5 gene at position } \\
\text { 1691) } \\
\text { - Prothrombin G20210A, a mutation in Prothrombin (at } \\
\text { position } 20210 \text { in the 3' untranslated region of the gene) } \\
\text { Type I: } \\
\text { - Antithrombin III deficiency } \\
\text { - Protein C deficiency } \\
\text { - Protein S deficiency } \\
\text { - Factor XIII mutation } \\
\text { - Familial dysfibrinogenemia }\end{array}$ & $\begin{array}{l}\text { - } \text { Antiphospholipid syndrome } \\
\text { - } \text { Paroxysmal nocturnal hemoglobinuria (PNH) } \\
\text { - } \text { Sickle cell anemia } \\
\text { - Myeloproliferative disorders } \\
\text { - } \text { Cancer, particularly when metastatic } \\
\text { - } \text { Nephrotic syndrome } \\
\text { - } \text { Pregnammatory bowel disease (ulcerative colitis and Crohn's disease) } \\
\text { - Hormone replacement therapy } \\
\text { - Morbid obese }\end{array}$ \\
\hline
\end{tabular}

Table 6. Primary end points.

\begin{tabular}{ccc}
\hline Parameter investigate & Number of patients & Percentage \\
Bleeding (possible \& definite) & 13 & $16.25 \%$ \\
VTE & $1.25 \%$ \\
Cardiovascular events & 2 & $2.5 \%$ \\
\hline
\end{tabular}


Table 7. Secondary end points.

\begin{tabular}{|c|c|c|c|}
\hline Parameter investigate & Sub-title & Number of patient & Percentage \\
\hline \multirow{3}{*}{$\begin{array}{l}\text { Contraindications }(\mathrm{C} / \mathrm{I}) \text { for the use } \\
\text { of LMWH at the time of } \\
\text { prescribing }\end{array}$} & Present & 11 & $13.75 \%$ \\
\hline & Absent & 67 & $83.75 \%$ \\
\hline & History and initial investigation were not sufficient to detect C/I & 2 & $2.5 \%$ \\
\hline \multirow{2}{*}{ Type of $C / I^{¥}(N=11)$} & Uncontrolled hypertension at the time of prescribing & 10 & $90.9 \%$ \\
\hline & Active major bleeding & 1 & $9.1 \%$ \\
\hline \multirow{2}{*}{ Indication validity } & Valid & 57 & $71.25 \%$ \\
\hline & Not valid & 23 & $28.75 \%$ \\
\hline \multirow{2}{*}{ Bleeding risk ${ }^{\diamond}$} & IMPROVE bleeding score $<7$ & 65 & $81.25 \%$ \\
\hline & IMPROVE bleeding score $\geq 7$ & 15 & $18.75 \%$ \\
\hline \multirow{4}{*}{ Dose appropriateness } & Appropriate & & $56.25 \%$ \\
\hline & Not appropriate & & $40 \%$ \\
\hline & Not applicable & & $1.25 \%$ \\
\hline & Not able to verify the appropriateness of the dose & & $2.5 \%$ \\
\hline \multirow{2}{*}{ Measuring platelets at baseline } & Yes & 75 & $93.75 \%$ \\
\hline & No & 5 & $6.25 \%$ \\
\hline \multirow{2}{*}{$\begin{array}{l}\text { Appropriate monitoring of } \\
\text { platelets }^{\phi}\end{array}$} & Yes & 31 & $38.75 \%$ \\
\hline & No & 49 & $61.25 \%$ \\
\hline \multirow{5}{*}{$\begin{array}{l}\text { Adverse drug events other than } \\
\text { bleeding }\end{array}$} & Osteoporosis & 0 & $0 \%$ \\
\hline & Heparin induced thrombocytopenia & 0 & $0 \%$ \\
\hline & Possible heparin induced thrombocytopenia (HIT) & 2 & $2.5 \%$ \\
\hline & Hyperkalemia & 0 & $0 \%$ \\
\hline & Hypersensitivity & 0 & $0 \%$ \\
\hline
\end{tabular}

${ }^{\ddagger}$ Indication validity to prevent against VTE based on padua score ( $\geq 4$ is valid);

${ }^{\circ}$ Bleeding risk is assessed by the IMPROVE Bleeding risk Score;

${ }^{\sharp} \mathrm{C} / \mathrm{I}[24]$ [25]:

Hypersensitivity to enoxaparin, heparin, pork products, or any component of the formulation (including benzyl alcohol in multiple-dose vials); thrombocytopenia associated with a positive in vitro test for antiplatelet antibodies in the presence of enoxaparin; active major bleeding

Canadian labeling: Additional contraindications (not in U.S. labeling): Use of multiple-dose vials in newborns or premature neonates; history of confirmed or suspected immunologically-mediated heparin-induced thrombocytopenia; acute or subacute bacterial endocarditis; major blood clotting disorders; active gastric or duodenal ulcer; hemorrhagic cerebrovascular accident (except if there are systemic emboli); severe uncontrolled hypertension (cut off $\geq 170 / 90$ ); diabetic or hemorrhagic retinopathy; other conditions or diseases involving an increased risk of hemorrhage; injuries to and operations on the brain, spinal cord, eyes, and ears; spinal/epidural anesthesia when repeated dosing of enoxaparin (1 mg/kg every 12 hours or $1.5 \mathrm{mg} / \mathrm{kg}$ daily) is required, due to increased risk of bleeding.

$\$$ Monitoring platelet counts every other day for 14 days of starting the medication.

\section{Discussion}

Medication use evaluation and adherence to guidelines are criticle parameters to optimize patient care, effective use of medications and avoiding undesirable effects. The importance of VTE prophylaxis was demonstrated by Samama et al. (1999) and Leizorovicz et al. (2004), where VTE prophylaxis resulted in reducing the risk of developing VTE by 50\% [11] [12]. However, optimal prophylaxis is achieved by the appropriate use of pharmacological and/or mechanical methods. In our study, 57 patients $(71.25 \%)$ patients had a Padua score of $\geq 4$, which validate the use of VTE prophylaxis measure. However, 13 patients (22.8\%) out of the 57 had a high risk of bleeding according to the IMPROVE score $(\geq 7)$ [10]. Hence, as per the CHEST guidelines, patients with high bleeding risk should have been placed on a mechanical prophylaxis methods [6]. Yet, if VTE risk is high, and clinical judgments favor the use of a pharmacological agent, these agents should be used with caution and alerts should appear in the CPOE. Decousus et al. (2011), conducted an observational study using data from the IMPROVE trial to assess the in-hospital bleeding incidence, and identify the risk factors for bleeding in acutely ill medical patients [10]. The study revealed that the bleeding risk begins to increase exponentially in patients with IMPROVE score $\geq 7$ [10]. 
The relationship between an IMPROVE score of $\geq 7$ and bleeding was examined in our study as well via a chi-square test, showing the existence of a statistically significant relationship between the 2 parameters $(p=$ 0.047) as seen in Table 8. Accordingly, our study and Decousus et al. (2011), reached to the same conclusion which is, the benefit of utilizing the IMPROVE score helps to prevent major and non-major but clinically significant bleeding incidences [10]. Nevertheless, one of the major drawbacks of the IMPROVE bleeding risk calculator is the absence of a score assigned to medications with the potential to cause or increase the risk of bleeding. For the purpose of this study, aspirin and clopidogrel use alongside with LMWH was explored. Out of the 13 patients who had bleeding during the hospitalization, eight (61.53\%) were on aspirin and/or clopidogrel as displayed in Figure 1. The co-existence of a relationship between the use of anti-platelets alongside with LMWH and increase the risk of bleeding was assessed in our study via chi-square to demonstrate a relationship that is statistically not significant $(p>0.05)$.

The presence of C/I at the time of prescribing LMWH is an end point that was explored in our study. If a C/I(s) for the use of pharmacological VTE prophylaxis is/are present, the CHEST guidelines recommends utilizing mechanical prophylaxis instead. Use of pharmacological agents in such situations should be exercised with an extreme caution if clinically relevant. Bateman et al. (2013) mentioned that despite the improvement in VTE risk assessment documentation, the percentage of patients who received LMWH when a contraindication is present did not change, $14 \%$ in 2009 versus $15 \%$ in 2010 (95\% CI: $-16.5 \%$ to $17.2 \% ; p=0.97)$ [8]. According to the data of our study, eleven patients (13.75\%) had C/I(s) at the time of prescribing a LMWH.

Table 8. Chi square test.

\begin{tabular}{|c|c|c|c|c|}
\hline \multirow{2}{*}{ IMPROVE score } & \multicolumn{2}{|c|}{ Bleed } & \multirow{2}{*}{ Total } & \multirow{2}{*}{$P$ value } \\
\hline & Yes & No & & \\
\hline$\geq 7$ & 5 & 10 & 15 & \multirow{2}{*}{0.047} \\
\hline$<7$ & 8 & 57 & 65 & \\
\hline
\end{tabular}

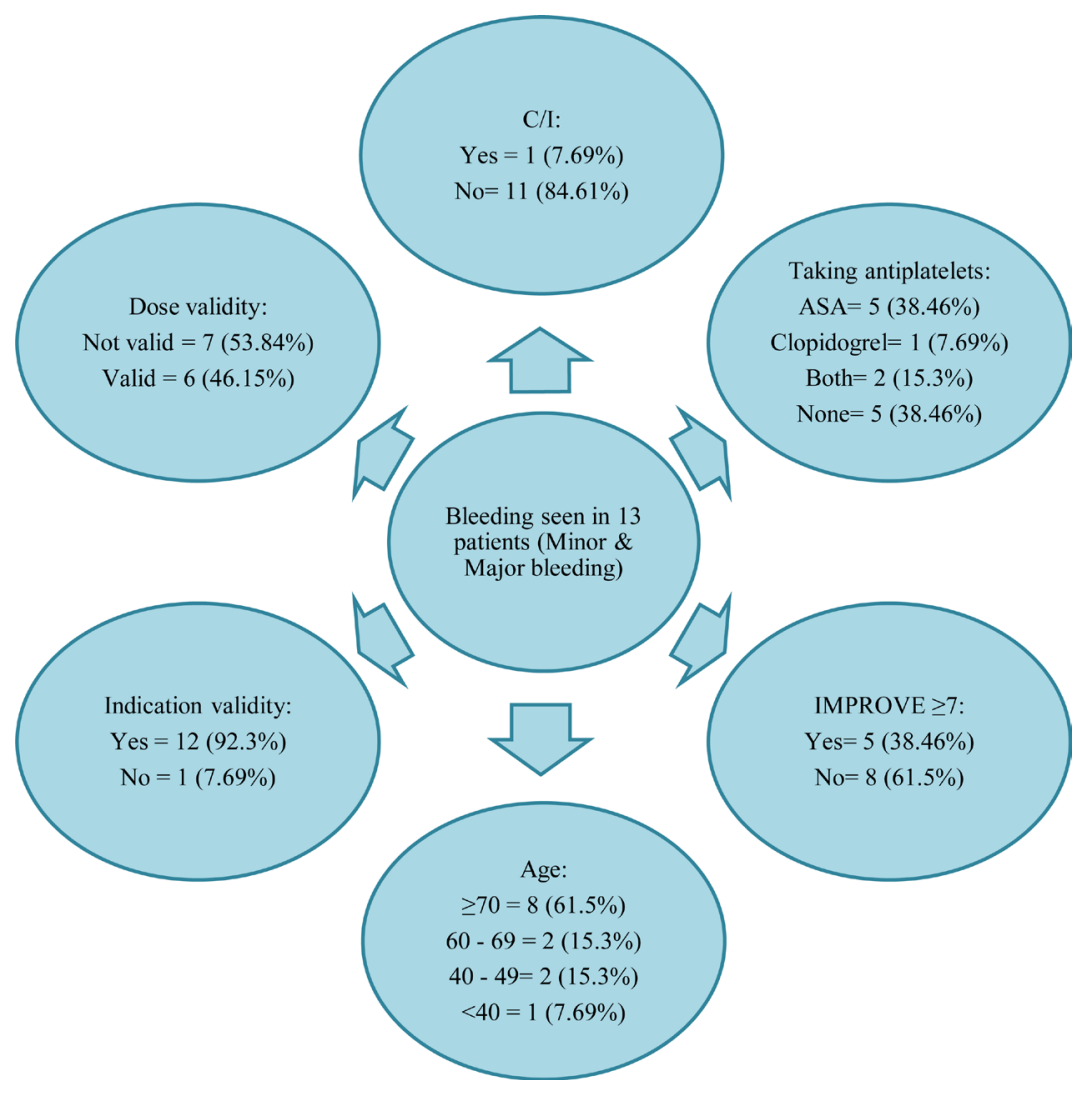

Figure 1. Further investigation in the bleeding incidences. 
The possibility of the existence of a relationship between increased age and risk of bleeding was explored via chi square test. Because the majority of patients admitted to the medical wards in Tawam hospital are geriatrics ( $\geq 60$ years old), and in the IMPROVE scoring system an age of $\geq 85$ is assigned to a higher scoring power; such an analysis thought to be prominent. Also, as it is shown Figure 1, 10 out of the 13 bleeding incidences (76.8\%) were $\geq 60$ years old. Yet, the results of the analysis indicated that there is no statistically significant association between age $\geq 60$ and bleeding $(p>0.05$ ). On the other hand, only one patient developed VTE while on the pharmacological prophylactic measure during the study period. On further investigation, it has been found that the patient who developed VTE had a Padua score of $>4$ and IMPROVE score $<7$. The patient was morbidly obese with BMI > 40 and was prescribed 40 mg SC every 24 hours instead of every 12 hours, which might have resulted in developing VTE.

Appropriate dosing is essential to provide optimal protection when pharmacological methods are chosen. Weight in kilograms, BMI and kidneys function should be taken into consideration when deciding on the dose of LMWH. The appropriate doses for VTE prophylaxis are available in Table 8 as per the CHEST 2012 guidelines. Inappropriate dosing which could be under or over dosing is one of the contributing factors in the failure of optimal prophylaxis or development of undesirable effects (i.e. bleeding). Pugh et al. (2005) and Jetha et al. (2007) pointed out that such an issue is not uncommon and the percentages of inappropriate dosing were $28.7 \%$ and $16 \%$, respectively [13] [14]. However, in our study the percentage was even higher and reached $40 \%$. As mentioned previously, the single incidence of VTE that was developed during our study was most probably related to dose inappropriateness.

The optimal duration for the use of pharmacological VTE prophylactic agents is still considered to be an area of controversy. Yu et al. (2007) conducted a retrospective study to evaluate the compliance to the $6^{\text {th }}$ ACCP consensus conference on antithrombotic therapy guidelines for the prevention of VTE in hospitals [15]. The study mentioned that $11.4 \%$ of medical patients with risk of VTE had an inappropriate duration for using VTE prophylaxis [15]. The optimal duration of thromboprophylaxis is to be continued until the time of discharge for the majority of medical patients having VTE risk according to Selby and Geerts (2009) [16]. However, our study did not explore this point; that is due to the fact that a large portion of patients hadun-renewed orders of LMWH specifically if they were hospitalized $>7$ days. Also, if LMWH was stopped before discharge when hospitalization is $<7$ days, justifications for stopping the medication was not documented.

As per guidelines, LMWH needs to be monitored appropriately to prevent bleeding and the development of rare but potentially life threatening adverse event which is heparin induced thrombocytopenia (HIT). Although HIT is less common with the use of LMWH compared to UFH, it is a life threatening condition that occurs in up to $5 \%$ of patients. HIT occurs because of the production of autoantibody against the endogenous platelet factor $4 \%$ (PF4), that complexes with heparin. This will activate platelets, resulting in catastrophic arterial and venous thrombosis [17]. Thus, platelet counts need to be monitored every other day in the first 14 days of prescribing LMWH or UFH. In our study, 49 patients (61.25\%) had an inappropriate monitoring while on LMWH, and two patients were suspected to have developed HIT. However, after challenging the results of these 2 patients using the pretest probability of heparin-induced thrombocytopenia (4-T's score) in Table 9 obtained from Lo et al. (2006), the results revealed that one of the patients had a low probability while the other had an intermediate probability [18].

Of note, in the study site VTE risk is assessed via a calculator that is similar to the Padua score which is available in the CPOE system-Cerner Millennium ${ }^{\circledR}$. However, a tool to assess the bleeding risk is not yet available in the CPOE, which is essential for safe and effective VTE prophylaxis.

Recommendations based on the results of this study were as follows; adopting institutional guidelines based on the CHEST recommendations for the use of LMWH to prevent against VTE, to enhance initial assessment, optimize drug dosing (inappropriate in 40\%) and monitoring while on LMWH (inappropriate in 49\%). In addition, optimizing the use of risk assessments tools and adding a bleeding risk assessment tool (IMPROVE) to the electronic VTE assessment tool in the health information system. Furthermore, the IMPROVE score had a

Table 9. 4-T’s score interpretation [18].

\begin{tabular}{cc}
\hline Points & Probability \\
\hline 0 to 3 points & Low probability \\
4 to 5 points & Intermediate probability \\
6 to 8 points & High probability \\
\hline
\end{tabular}


limitation of not assigning a score to anti-platelets. Hence, if the score will be adapted, it would be reasonable to assign a score to the use of apirin and/or clopidogrel.

\section{Conclusion}

In conclusion, various factors have been found to play a significant role in the ineffectiveness and lack of safety while on VTE prophylaxis. These factors include: poor adherence to VTE guidelines, inappropriate dosing and monitoring, and not utilizing risk assessment tools. Despite the fact that Padua VTE risk assessment tool is available in the health information system, reluctance to use it and/or poor documentation is not uncommon. The IMPROVE score is another important tool that needs to be incorporated in the health information system. Not assigning a score to the anti-platelets in the IMPROVE score is a limitation which was identified during this study; as $61.45 \%$ of the bleeding cases were on at least one anti-platelet agent. On the other hand, this study was not without limitations; the small sample size $(\mathrm{N}=80)$ and the inability to evaluate the appropriateness of the duration of VTE prophylaxis were the most evident ones.

\section{Acknowledgements}

The authors thank “Tawam Hospital in Affiliation with John Hopkins” for supporting carrying this study.

\section{References}

[1] Thompson, B. and Hales, C. (2014) Overview of Acute Pulmonary Embolism. http://www.uptodate.com/contents/overview-of-acute-pulmonary-embolism?source=search result\&search=PE\%2Fdvt \&selectedTitle $=4 \% 7 \mathrm{E} 150$

[2] Anderson Jr., F.A., Zayaruzny, M., Heit, J.A., Fidan, D. and Cohen, A.T. (2007) Estimated Annual Numbers of US Acute-Care Hospital Patients at Risk for Venous Thromboembolism. American Journal of Hematology, 82, 777-782. http://dx.doi.org/10.1002/ajh.20983

[3] Dismuke, S. and Wagner, E. (1986) Pulmonary Embolism as a Cause of Death. The Changing Mortality in Hospitalized Patients. JAMA, 255, 2039. http://dx.doi.org/10.1001/jama.1986.03370150081032

[4] Horlander, K.T., Manninom, M. and Leeper, KV. (2003) Pulmonary Embolism Mortality in the United States, 19791998: An Analysis Using Multiple-Cause Mortality Data. Archives of Internal Medicine, 163, 1711. http://dx.doi.org/10.1001/archinte.163.14.1711

[5] Chisholm-Burns, M., Wells, B., Schwinghammer, T., Malone, P., Kolesar, J., Rotschafer, J. and Dipiro, J. (2008) Pharmacotherapy: Principles \& Practice. The McGraw-Hill Companies, Inc., New York.

[6] Khan, S., Dunn, A., Klein, R., et al. (2012) Prevention of VTE in Nonsurgical Patients: Antithrombotic Therapy and Prevention of Thrombosis, 9th ed: American College of Chest Physicians Evidence-Based Clinical Practice Guidelines. CHEST, 141, e195S-e226S. http://dx.doi.org/10.1378/chest.11-2296

[7] Scaglione, L., Piobbici, M., Pagano, E., Ballini, L., Tamponi, G and Ciccone, G. (2005) Implementing Guidelines for Venous Thromboembolism Prophylaxis in a Large Italian Teaching Hospital: Lights and Shadows. Haematologica, 90, 678-684.

[8] Bateman, A., Sheaff, R., Child, S., et al. (2013) The Implementation of NICE Guidelines on Venous Thromboembolism Risk Assessment and Prophylaxis; A Before-After Observational Study to Assess the Impact on Patient Safety Across Four Hospitals in England. BioMed Central, 13, 1-7.

[9] CPOE : Cerner.com. http://www.cerner.com/solutions/Hospitals_and_Health_Systems/CPOE/

[10] Decousus, H., Tapson, V., Bergmann, J., et al. (2011). Factors at Admission Associated With Bleeding Risk in Medical Patients; Findings from the IMROVE Investigators. CHEST, 139, 69-79. http://dx.doi.org/10.1378/chest.09-3081

[11] Leizorovicz, A., Cohen, A.T., Turpie, A.G., Olsson, C.G., Vaitkus, P.T. and Goldhaber, S.Z. (2004) Randomized, Placebo-Controlled Trial of Dalteparin for the Prevention of Venous Thromboembolism in Acutely Ill Medical Patients. Circulation, 110, 874-879. http://dx.doi.org/10.1161/01.CIR.0000138928.83266.24

[12] Samama, M., Cohen, T, Darmon, J., et al. (1999) A Comparison of Enoxaparin with Placebo for the Prevention of Venous Thromboembolism in Acutely Ill Medical Patients. Prophylaxis in Medical Patients with Enoxaparin Study Group. New England Journal of Medicine, 341, 793-800. http://dx.doi.org/10.1056/nejm199909093411103

[13] Jetha, L. (2007) A Drug Usage Review of Therapeutic Doses of Enoxaparin at Barnet and Chase Farm Hospitals. London Pharmacy Education and Training Pzifer Project Awards.

http://www.londonpharmacy.nhs.uk/educationandtraining/prereg/pfizerProjectAwards2007/leila\%20jetha\%20Barnet\% 
20and\%20Chase\%20Farm\%20Hospital\%20Trust.pdf

[14] Pugh, M., Fincke, B., Bierman, A., et al. (2005) Potentially Inappropriate Prescribing in Elderly Veterans: Are We Using the Wrong Drug, Wrong Dose, or Wrong Duration? Journal of the American Geriatrics Society, 53, 1282-1289. http://dx.doi.org/10.1111/j.1532-5415.2005.53402.x

[15] Yu, H., Dylan, M., Lin, J. and Dubois, R. (2007) Hospitals’ Compliance with Prophylaxis Guidelines for Venous Thromboembolism. American Journal of Health-System Pharmacy, 64, 69-76. http://dx.doi.org/10.2146/ajhp060115

[16] Selby, R. and Geerts, W. (2009) Prevention of Venous Thromboembolism: Consensus, Controversies, and Challenges. American Society of Hematology, 2009, 286-292. http://dx.doi.org/10.1182/asheducation-2009.1.286

[17] Coutre, S. (2014) Clinical Presentation and Diagnosis of Heparin-Induced Thrombocytopenia. http://www.uptodate.com/contents/clinical-presentation-and-diagnosis-of-heparin-inducedthrombocytopenia?source=se arch_result\&search=HITT\&selectedTitle=1\%7E150

[18] Lo, G.K., Juhl, D., Warkentin, T., Sigouin, C., Eicheler, P. and Greinacher, A. (2004) Evaluation of Pretest Clinical Score (4 T's) for the Diagnosis of Heparin-Induced Thrombocytopenia in Two Clinical Settings. Journal of Thrombosis and Haemostasis, 4, 759-765. http://dx.doi.org/10.1111/j.1538-7836.2006.01787.x

[19] Duplaga, B., Rivers, C. and Nutescu, E. (2001). Dosing and Monitoring of Low-Molecular-Weight Heparins in Special Populations. Pharmacotherapy, 21, 218-234. http://dx.doi.org/10.1592/phco.21.2.218.34112

[20] King, C., Holley, A., Jackson, J., Shorr, A. and Moores, L. (2007) Twice Daily vs Three Times Daily Heparin Dosing for Thromboembolism Prophylaxis in the General Medical Population. CHEST, 131, 507-516. http://dx.doi.org/10.1378/chest.06-1861

[21] Nutescu, E., Spinler, S., Wittkowsky, A. and Dager, W. (2009) Low-Molecular-Weight Heparins in Renal Impairment and Obesity: Available Evidence and Clinical Practice Recommendations across Medical and Surgical Settings. Annals of Pharmacotherapy, 43, 1064-1083. http://dx.doi.org/10.1345/aph.1L194

[22] Phung, O., Kahn, S., Cook, D. and Murad, M. (2011) Dosing Frequency of Unfractionated Heparin Thromboprophylaxis: A Meta-Analysis. CHEST, 140, 374-381. http://dx.doi.org/10.1378/chest.10-3084

[23] Scholten, D., Hoedema, R. and Scholten, S. (2002) A Comparison of Two Different Prophylactic Dose Regimens of Low Molecular Weight Heparin in Bariatric Surgery. Obesity Surgery, 12, 19-24. http://dx.doi.org/10.1381/096089202321144522

[24] Enoxaparin. In: DRUGDEX® System (internet database). Thomson Micromedex, Greenwood Village, Colorado, USA. http://www.thomsonhc.com

[25] Enoxaparin: Drug information. (2013). http://www.uptodate.com/contents/enoxaparin-drug-information?source=search_result\&search=enoxaparin\&selectedT itle=1\%7E96 